\title{
Phase I clinical study of the acute and subacute safety and proof-of-concept efficacy of carbohydrate-derived fulvic acid
}

This article was published in the following Dove Press journal:

Clinical Pharmacology:Advances and Applications

16 February 2012

Number of times this article has been viewed

\author{
Justin John Gandy \\ Johanna Petronella Meeding \\ Jacques René Snyman \\ Constance Elizabeth Jansen \\ van Rensburg
}

Department of Pharmacology,

Faculty of Health Sciences,

University of Pretoria, Pretoria,

South Africa
Correspondence: Justin John Gandy PO Box 477, Newlands, Pretoria 0049, South Africa

$\mathrm{Tel}+27$ II 6350787

Fax +270865530787

Email gandy.justin@gmail.com
Background: The purpose of this research was to determine the acute and subacute safety and proof-of-concept efficacy of carbohydrate-derived fulvic acid (CHD-FA).

Methods: In this double-blind study, 30 male volunteers with predetermined atopy were randomly assigned to either Group A or Group B, each consisting of 15 participants. In part 1 of the study, the groups were administered increasing amounts of CHD-FA, ranging from $5 \mathrm{~mL}$ to $40 \mathrm{~mL}$, provided that no adverse events had occurred at the previous dosage. In part 2, Group A participants received $20 \mathrm{~mL}$ of $3.8 \%$ CHD-FA twice daily for 3 days and were monitored for a week. Because no adverse events occurred, Group B received $40 \mathrm{~mL}$ of 3.8\% CHD-FA twice daily for a period of 3 days. In part 3, both groups received either $40 \mathrm{~mL}$ of $3.8 \% \mathrm{CHD}$-FA or placebo twice daily for a period of one week, followed by a one-week washout period before crossover to the alternative treatment schedule. Parameters used to establish safety were electrocardiography, a physical examination, a health questionnaire, and hematology and biochemistry, determined at baseline, during regular calculated intervals, and at the end of each part of the study. A skin prick test was done as part of the screening process and, from the result, the allergen the participant was most allergic to was then selected, along with the positive histamine and negative control to be repeated at the start and end of each respective stage.

Results: Safety parameters remained constant throughout the trial. A significant decrease in skin prick test results was observed.

Conclusion: No severe adverse events occurred, establishing that CHD-FA to be safe at doses up to $40 \mathrm{~mL}$ twice daily for a week and that at this dosage CHD-FA acts as an anti-inflammatory agent. These findings confirm earlier animal data.

Keywords: CHD-FA, safety, efficacy, anti-inflammatory

\section{Introduction}

\section{Humic substances}

Humic substances are present wherever organic matter is being decomposed, ${ }^{1}$ and can be defined as “... a general category of naturally occurring, biogenic, heterogeneous organic substances that can generally be characterized as being yellow to black in color and of high molecular weight". Humic acids are found in soils, waters, sewage, compost heaps, marine and lake sediments, peat bogs, carbonaceous shales, lignites, and brown coals. Humic substances can be subdivided into humic acid, fulvic acid, and humin. The average molecular weight of humic substances may range from 500 to $5000 \mathrm{Da}$ for fulvic acid to 3000 to $1,000,000 \mathrm{Da}$ for humic acid. ${ }^{2}$

The Department of Pharmacology at the University of Pretoria has been involved in researching the novel medicinal properties and applications of humic acid and 
fulvic acid since 2000. Oxifulvic acid, so-called because it is derived from controlled wet oxidation of carbon-containing coal, was used for topical application research. ${ }^{3,4}$ Fulvic acid $4.5 \%$ and $9 \%$ showed equivalence when compared with diclofenac sodium $1 \%$ and betamethasone $0.1 \%$ in a murine model when applied topically to suppress a cutaneous inflammatory response, and found to have none of the adverse effects seen with the aforementioned anti-inflammatory agents. ${ }^{3}$ In feline and canine models, fulvic acid showed antiinflammatory properties by inhibiting the accumulation of pus in pyotraumatic dermatitis when applied topically. ${ }^{5}$

Carbohydrate-derived fulvic acid (CHD-FA) is a new heavy metal-free carbohydrate-derived fulvic acid. In a topical toxicity and sensitization study, 60 6-8-week-old female $\mathrm{Balb} \mathrm{C}$ mice were used. The mice were randomized into three groups consisting of 20 mice per group. Group 1 received ung emulcificans aqueosum (UEA) only, Group 2 received CHD-FA, and Group 3 received CHD-FA neutralized to a $\mathrm{pH}$ of 5.5. From day 8 , they received the products topically on the left ear twice a day for 30 days (up to 38 days). The amount of CHD-FA preparation used was calculated using $8 \mathrm{mg}$ CHD-FA $/$ mouse, or $400 \mathrm{mg} / \mathrm{kg}$ body weight, twice a day. Morbidity was determined on a daily basis by evaluation of reduced food and water intake resulting in weight loss (more than $20 \%$ original weight), observation of abnormal movement (particularly pertaining to the ability of the animal to obtain food and water), and ease of breathing. Blood samples ( $500 \mu \mathrm{L} /$ mouse) were drawn after termination at the end of the study to determine kidney and liver enzyme levels (creatinine and gamma-glutamyl transferase, respectively). Analysis of variance was used to analyze data. The data suggested that the CHD-FA, when applied topically, did not produce any hypersensitivity reactions and was nontoxic with regards to liver and kidney function in mice over a period of one month (data on file, Department of Pharmacology, University of Pretoria).

A 30-day toxicity study was done using 60 female 6-8-week old Sprague-Dawley rats. Animals in the experimental group $(n=20)$ received a single oral dose (by gavage) of $100 \mathrm{mg} / \mathrm{kg}$ body weight/day of CHD-FA (potassium salt) neutralized to a $\mathrm{pH}$ of 5.5 in distilled water as a $1.0 \mathrm{~mL}$ bolus per day for 90 days. Control animals $(n=20)$ received an oral dose (by gavage) of $1.0 \mathrm{~mL}$ distilled water per day to control for the procedure used in the experimental group. A third group of 20 animals was added and received half the dose of the experimental group. The animals were weighed daily and monitored for pain and distress (behavioral changes).
Toxicity was determined by evaluation of reduced food and water intake resulting in weight loss, observation of abnormal movement, and ease of breathing. Blood samples $(500 \mu \mathrm{L} / \mathrm{rat})$ were drawn from the animals at the beginning and end of the study for hematological analysis and kidney and liver enzyme levels. The data suggested that the product was nontoxic with regards to liver and kidney function in rats over a period of 6 months, when administered orally. ${ }^{6}$

In healthy volunteers, fulvic acid had no significant effect on safety parameters and did not induce sensitization when applied topically. Fulvic acid cream $4.5 \%$ caused inhibition of the elicited inflammatory reaction, and this was comparable with hydrocortisone. ${ }^{2}$ A new product with a lower metal content was developed for systemic application. An investigation of the safety of this product administered by gavage in rats $(175 \mathrm{mg} / \mathrm{kg})$ was performed. The rats showed no sign of discomfort, and results obtained from blood specimens sent to Clinical Pathology Laboratories indicated that the CHD-FA administered systemically for a period of 6 weeks was indeed safe. ${ }^{6}$

The in vivo human data demonstrating topical efficacy and safety as well as significant animal data supporting in vivo efficacy and safety after systemic use, as well as observational data confirming safety of oral administration of this complimentary or alternative medicine in humans motivated this in vivo safety study. The aim of this research was to establish the acute and subacute safety of CHD-FA over the anticipated dose range and also to determine if CHD-FA potentially has anti-inflammatory properties that would warrant further investigation.

\section{Materials and methods}

In this double-blind study, 30 male volunteers with predetermined atopy were randomly assigned to Group A or Group B on arrival by random allocation of an alpha numeric, eg, A06 or B11 from a computer-randomized list, each consisting of 15 participants. The participants were recruited into the study after approval was obtained from the University of Pretoria research ethics committee.

\section{Part I: acute exposure safety}

A one-off oral dosage of either $5 \mathrm{~mL}$ and $20 \mathrm{~mL}$ or $10 \mathrm{~mL}$ and $40 \mathrm{~mL}$ (3.8\%) CHD-FA was administered and the volunteers were monitored at various intervals for 72 hours, with a final visit 7 days after oral dosage, with the following parameters being monitored: vital parameters, clinical investigation, patient perception of general health questionnaire, electrocardiography, and hematology and biochemistry, including full 
blood count and liver and kidney function. After successful completion of part 1, ie, no adverse events that were of clinical relevance, part 2 was commenced.

\section{Part 2: subacute toxicity}

This was a 3-day exposure in the same volunteers, ie, $20 \mathrm{~mL}$ or $40 \mathrm{~mL}$ of $3.8 \%$ CHD-FA was administered twice per day, with the following parameters being monitored at various intervals: vital parameters, clinical investigation, patient perception of general health, electrocardiography, hematology and biochemistry, including full blood count and liver and kidney function. After successful completion of part 2, ie, no adverse events that were of clinical relevance, part 3 was commenced.

\section{Part 3: proof of concept}

This was a 7-day exposure in the same volunteers, ie, $40 \mathrm{~mL}$ of $3.8 \%$ CHD-FA or placebo administered twice per day, followed by a two-week washout period and subsequent crossover, with the following parameters being monitored at various intervals: skin pricks, vital parameters, clinical investigation, patient perception of general health, electrocardiography, and hematology and biochemistry, including full blood count and liver and kidney function. For each participant, the skin prick test was done as part of the screening process and from the result the allergen to which the participant was most allergic was then selected along with the positive histamine and negative control to be repeated at the start and end of each respective stage. Wheals were measured using a digital caliper 10 minutes after exposure.

\section{Outcomes}

Outcomes included safety, assessed by clinical parameters and vitals. Biochemistry included urea, uric acid, creatinine, chloride, potassium, sodium, gamma-glutamyl transferase, alkaline phosphatase, aspartate aminotransferase, and alanine aminotransferase. Hematology included a full blood count and differential, with hemoglobin and white and red blood cells. All biochemistry and hematology measurements were done in an ISO (International Organization for Standardization) accredited laboratory using a Roche P800 and Siemens Advia 2120, respectively. Electrocardiograms were read by an independent clinician who reported on changes from baseline. Proof of concept was determined as a significant $(P<0.05)$ reduction in size of wheal formation post CHD-FA treatment.

\section{Inclusion criteria}

Male patients aged 18 years and older who had a pollen allergy and were not on antiallergic treatment were recruited into the study. Patients gave their written informed consent. Patients were otherwise healthy with no other systemic disease that could influence the immune response. Normal hematology and biochemistry values, electrocardiograms, and clinical investigations were confirmed before randomization.

\section{Exclusion criteria}

Women and subjects with systemic diseases, such as diabetes mellitus, kidney failure, liver failure, or autoimmune, hematologic, psychiatric, gastrointestinal, cardiovascular, or lung disease that could significantly compromise health were excluded. Any immune system disease other than atopy was also an exclusion criterion, as were an inability to understand or give written informed consent, any abnormality in hematology or biochemistry values, alcoholism or drug addiction, and any type of immunosuppressant therapy.

\section{Treatment}

In the acute toxicity study, Group A received $5 \mathrm{~mL}$ and $20 \mathrm{~mL}$ of CHD-FA 3.8\% in syrup as single doses and Group B received $10 \mathrm{~mL}$ and $40 \mathrm{~mL}$ of CHD-FA $3.8 \%$ as a single dose. In the subacute toxicity study, Group A received $20 \mathrm{~mL}$ of CHD-FA $3.8 \%$ twice daily for 3 days and Group B received $40 \mathrm{~mL}$ of CHD-FA 3.8\% twice daily for a 3-day period. For proof of concept, both groups received either $40 \mathrm{~mL}$ of CHD-FA $3.8 \%$ or placebo for a 7-day period, followed by a 7-day washout period, then a crossover. All treatments were taken without food.

\section{Statistical analysis}

The results were analyzed using GraphPad Prism 4.0. The Wilcoxon rank test was used for the safety aspects of the study. For the proof of concept results, an analysis of covariance was used, with $P<0.05$ regarded as statistically significant when comparing the before and after results of the treated versus placebo groups, respectively.

\section{Results}

Twenty-one participants successfully completed the trial, one failed to comply after screening, one failed to comply at the first visit, one experienced an adverse event (namely hypertension which appeared to be unrelated to the study medication), and two subjects failed to comply during part 1 of the study. Four subjects were withdrawn as a result of either an arrhythmia or bradycardia that was present at baseline.

\section{Safety}

All safety parameters remained within normal limits for the duration of the acute phase of the trial, with only one subject 


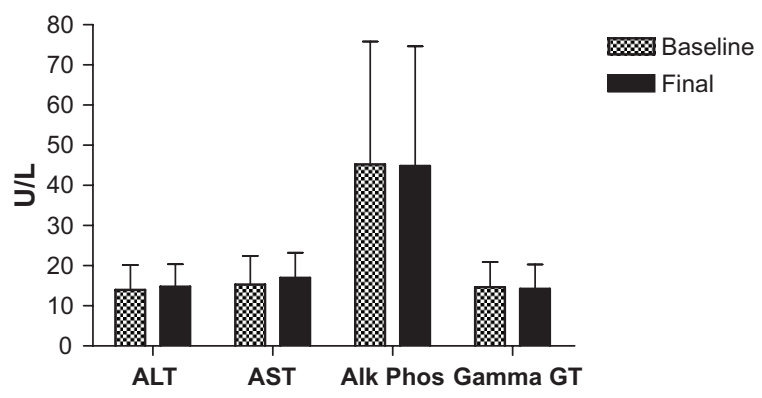

Figure I Liver function tests.

Abbreviations: ALT, alanine transaminase; AST, aspartate transminase; Alk Phos, alkaline phosphatase; Gamma GT, gamma glutamyl transpeptidase.

having elevated aspartate aminotransferase and alanine aminotransferase levels after $40 \mathrm{~mL}$ dosing, which was more likely to be associated with a viral infection rather than a side effect of the CHD-FA. These values did return to within normal limits. Due to the vast amount of testing done, the parameters of interest are tabulated below, illustrating the battery of tests used to determine safety, namely liver function (Figure 1) and kidney function (Figures 2 and 3), respectively.

\section{Efficacy}

With statistical analysis, using analysis of variance and adjusting for baseline, a significant difference was observed, with $P<0.05$ when comparing the before and after results of the treated versus placebo groups, respectively; $81 \%$ of the participants had a decreased wheal after CHD-FA treatment versus $62 \%$ of those treated with placebo (Table 1 ). Because there is no known method of detecting plasma levels of fulvic acid compounds, clinical outcome served as evidence of systemic exposure, ie, absorption. Side effects were monitored, and are summarized in Figure 4.

\section{Discussion}

\section{Safety}

With extensive safety testing, indicated by hematology and biochemistry markers, it can be stated with confidence

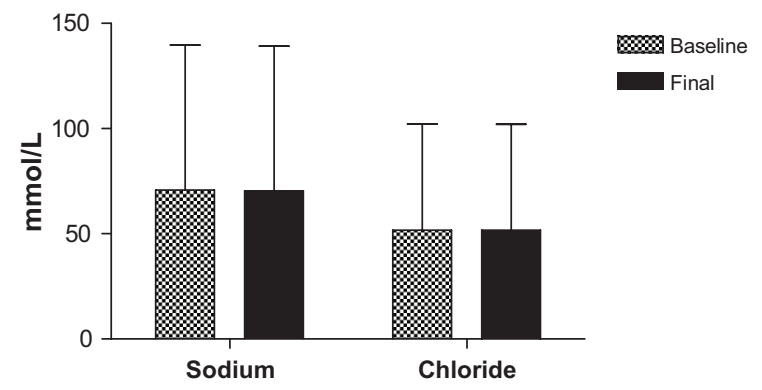

Figure 2 Kidney function tests.

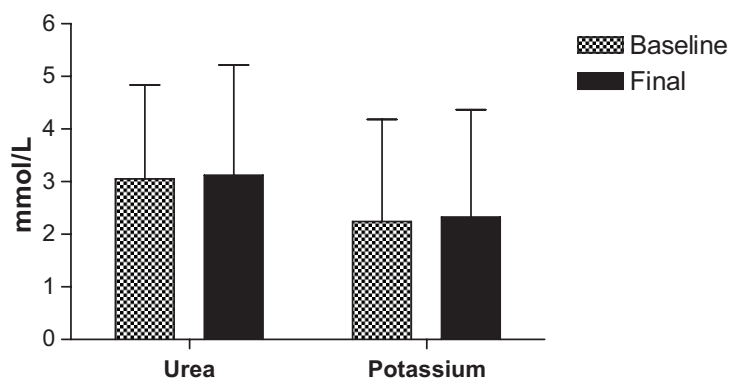

Figure 3 Kidney function tests.

that safety parameters were not affected in any way, demonstrating that the dose range of CHD-FA tested correlated well with that of the rat studies, in which no significant fluctuations in safety parameters were observed after 9 months of dosing. ${ }^{4}$

\section{Efficacy}

Comparing wheal measurements (an inflammatory response to an allergen), there was a significant difference between CHD-FA and placebo, ie, wheal measurements decreased significantly on CHD-FA, demonstrating that CHD-FA has a measurable in vivo effect on immediate hypersensitivity and warranting further investigations into the anti-inflammatory effect as well as the mechanism of action.

\section{Side effects}

The only noteworthy side effects were diarrhea, headache, and a sensation of a burnt or sore throat, all likely attributable to the low $\mathrm{pH}$ of the CHD-FA administered orally (the manufacturer's recommendation is to dilute the product in juice or water). The majority of these side effects occurred after ingestion of the upper limit of the CHD-FA dose range, ie, $40 \mathrm{~mL}$ twice daily. These side effects were not severe, and mostly subsided after a short period of time or after ingestion of food. The diarrhea resolved without medical intervention. After clinical review, the panel's decision was that the side

Table I Measurements of wheal diameter before and after in treated versus placebo groups with respect to skin prick tests

\begin{tabular}{llllll}
\hline & \multicolumn{3}{l}{ Diameter of wheal $(\mathbf{m m})$} & & \\
\cline { 2 - 3 } & Before & & & After & \\
\cline { 2 - 3 } \cline { 5 - 6 } & Mean & SD & & Mean & SD \\
\hline CHD-FA & 6.63 & 3.64 & & $4.97^{*}$ & 3.26 \\
Placebo & 7.03 & 4.15 & & 6.73 & 3.98 \\
\hline
\end{tabular}

Note: $* P<0.05$.

Abbreviations: SD, standard deviation; CHD-FA, carbohydrate-derived fulvic acid. 


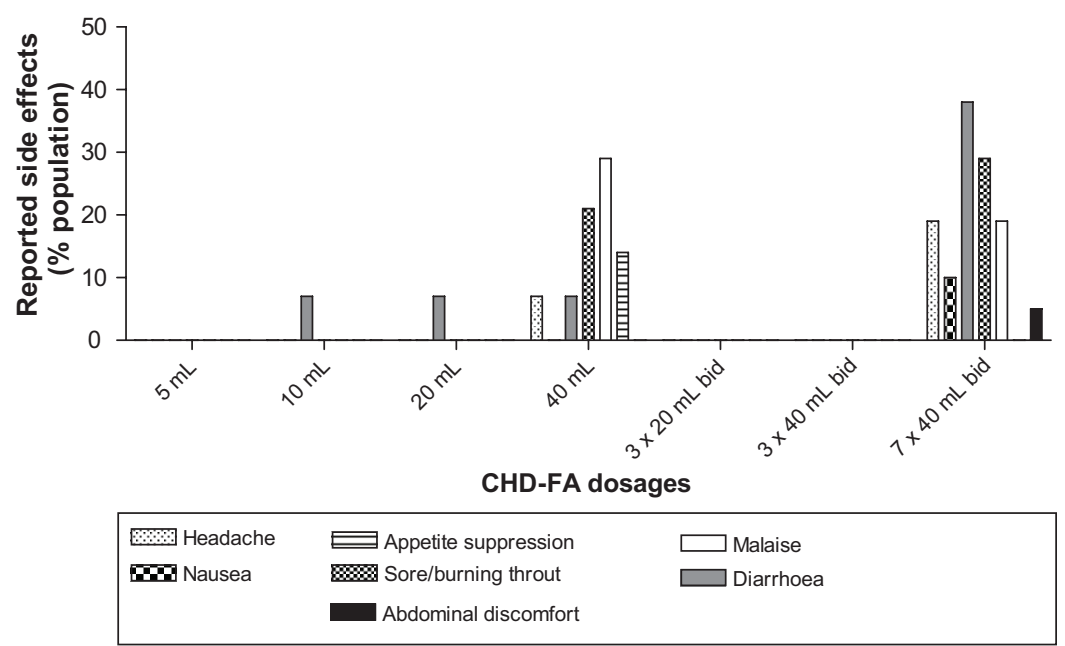

Figure 4 Side effects reported on CHD-FA.

Abbreviations: bid, twice daily; CHD-F, carbohydrate-derived fulvic acid.

effects observed were mild and transient, and not causally linked to CHD-FA.

\section{Conclusion}

No severe adverse events occurred, demonstrating CHD-FA to be safe at the dose tested. There was a significant decrease in wheal formation in the skin prick test, confirming that CHD-FA acts as an inhibitor of the immediate hypersensitivity reaction and that the product is systemically available. In light of the data from this research and previous toxicity studies, it can be stated that a $15 \mathrm{~mL}$ daily dose of CHD-FA diluted in water or juice, as recommended by the manufacturer, can be used safely.

\section{Disclosure}

The authors report no conflicts of interest in this work.

\section{References}

1. Hayes MHB, MacCarthy P, Malcom RL, Swift RS. The search for structure: setting the scene. In: Hayes MHB, MacCarthy P, Malcom RL, Swift RS, editors. Humic Substances II. In Search of Structure. Chichester, UK: John Wiley and Sons; 1989.

2. Sparks DL. Environmental Soil Chemistry. New York, NY: Academic Press; 2003.

3. Van Rensburg CEJ, Malfeld SCK, Dekker J. Topical application of oxifulvic acid suppresses the cutaneous immune response in mice. Drug Dev Res. 2001;53:29-32.

4. Snyman JR, Dekker J, Malfeld SCK, van Rensburg CEJ. Pilot study to evaluate the safety and therapeutic efficacy of topical oxifulvic acid in atopic volunteer. Drug Dev Res. 2002;57:4043.

5. Dekker J, Medlen CE. Fulvic acid and its use in the treatment of various conditions. Patent Corporation Application 1999 PTC/IB/9901649.

6. Sabi S, Vrey P, Van Rensburg CEJ. Carbohydrate-derived fulvic acid (CHD-FA) inhibits carrageenan-induced inflammation and enhances wound healing: Efficacy and toxicity study in rats. Drug Development Res. 2011; doi: 10.1002/ddr.20445.

\section{Publish your work in this journal}

Clinical Pharmacology: Advances and Applications is an international, peer-reviewed, open access journal publishing original research, reports, reviews and commentaries on all areas of drug experience in humans. The manuscript management system is completely online and includes a very quick and fair peer-review system, which is all easy to use.
Visit http://www.dovepress.com/testimonials.php to read real quotes from published authors. 